\title{
DIRECTIONS TO CONTRIBUTORS
}

General. The onus of preparing a paper in a form suitable for publication in the Journal of Dairy Research lies in the first place with the author. In their own interests authors are strongly advised to follow these directions carefully and to consult a current issue for guidance on details of layout and use of headings.

Typeseripts may be sent to the Editors at any time, and submission of a paper will be held to imply that it reports unpublished original work which is not under consideration for publication elsewhere.

Form of papkns. Papers should be typed with double sparing, and the title followed by the names and initials of the authors, women supplying one Christian name. The name and postal address of the laboratory must be stated.

Papers should be divided into the following parts in the order indicated: (a) Summary, brief and self-contained; (b) Introductory paragraphs, briefly explaining the object of the work but without giving an extensive account of the literature; $(c)$ Experimental or Methods; (d) Results; ( $p$ ) Discussion and Conclusions; (f) Acknowledgements without a heading; (g) References. Only with some exceptional types of material will headings different from $(c),(d)$ and $(e)$ be necessary.

The spelling adopted is that of the Shorter Oxford English Dirtionary. Underlining should be used only to indicate italics. Every effort should be made to avoid the use of footnotes. Proper nouns, including trade names, should be given a capital initial letter.

TABLEs. Each table should be numbered and should have a heading that enables its contents to be understood without reference to the text. Tables must be typed on separate sheets and their approximate positions indicated in the text.

Illustrations. Line drawings, which must be originals, should he numbered as Figures and photographs as Plates, in Arabic numerals. Drawings should be in indian ink, on Bristol board or cart ridge paper. However, a technique which may be more convenient to authors is to use a double-sized piece of tracing paper, or translucent graph paper faintly lined in blue or grey. folded down the centre with the drawing on one half and the other acting as a flyleaf.

Attarhed to every figure and plate there should be a translucent flyleaf cover on the outside of which should be written legibly: (a) title of paper and name of author; $(b)$ figure or plate number and explanatory legend; (c) the figures and lettering, which is intended to appear on the finished block, in the correct position relative to the drawing underneath. For each paper there should also be a separate typed sheet listing figure and plate numbers with their legends, and the approximate position of illustrations should be indicated in the text.

As a rule the photographs and diagrams should be about twice the size of the finished block and not larger over-all than the sheets on which the paper itself is typed. For general guidance in preparing diagrams, it is suggested that for a figure measuring 9 in. $\times 6$ in. all lines, axes and curves, should have a thickness of $0.4 \mathrm{~mm}$, thus - Graph symbols in order of preference should be $0, \Delta \boldsymbol{\Delta}$, $\square \square, x+$, and for a 9 in, $\times 6$ in. graph the open circles should be $\frac{f}{d}$ in. in diameter. The open triangles should he large enough to contain circles of $x^{\frac{3}{3}}$ in. diameter and the open squares circles of in. diameter. The crosses should have lines $\frac{1}{d}$ in. long. The block symbols should beslightly smaller than the corresponding open symbols. Scale marks on the axes should be on the inner side of each axis and should be $\frac{1}{d}$ in. long.

Referencrs. In the text references should be quoted by whichever of the following ways is appropriate: Arnold \& Barnard (1900); Arnold \& Barnard (1900a); Arnold \& Barnard (1900a, b); (Arnold \& Barnard, 1900). Where there are more than two authors all the surnames should be quoted at the first mention, but in subsequent citations only the first surname should be given thus, Brown et al. (1901). If there are six or more names, use el al. in first instance. Also, if the combinations of names are similar, repeat names each time, e.g. Brown, Smith \& Allen (1954); Brown, Allen \& Smith (1954).

References should be listed alphabetically at the end of the paper, title of journals being abbreviated as in the World List of Scientific Periodicals. Authors' initials should be included, and each reference should be punctuated in the typescript thus: Arnold, T. 13., Barnard, R. N. \& Compound, P. J. (1900). J. Dairy Res. 18, 158. References to books should include name of author, year of publication, title, town of publication and name of publisher in that order, thus, Arnold, T. B. (1000). Dairying. London: Brown and Chester.

It is the duty of the author to check all references and to ensure that the correct abbreviations are used.

Symbols and abBreviations. The symbols and abbreviations used are those of British Standard 1991: Part 1: 1954, Letter Symbols, Signs and Abbreviations.

Descriptions of solutions. Normality and molarity should be indicated thus: $\mathrm{N}-\mathrm{HCl}$, $0.1 \mathrm{M}-\mathrm{NaH}_{2} \mathrm{PO}_{4}$. The term ' $\%$ ' means $\mathrm{g} / 100 \mathrm{~g}$ solution. For $\mathrm{ml} / 100 \mathrm{ml}$ solution write $\%$ $(\mathrm{v} / \mathrm{v})^{\prime}$ and for $\mathrm{g} / 100 \mathrm{ml}$ solution write $\%(\mathrm{w} / \mathrm{v})^{\prime}$.

RePrints. Order forms giving quotations for reprints are sent to authors with their proofs. 


\section{CONTENTS OF VOL. 30, No. 1}

\section{Original Articles}

The occurrence and significance of blood in bovine milk. C. G. RAMMELL .

The action of rennin on casein. The disruption of the $\kappa$-casein complex. R. Beeby and Hs. Nitschmann

Action of rennet and other proteolytic enzymes on casein in casein-agar gels. G. C. Cheeseman.

The relationship between milk yield, composition and tissue damage in a case of subclinical mastitis. R. Watte and P. S. BlackBurn . .

The effect on the performance of growing pigs of the level of meal fed in conjunction with an unrestricted supply of whey. K. G. MrTCHELL and P. H. Sedgwick

Studies on the properties of New Zealand butterfat. VI. Comparison of the properties and vitamin A potencies of butterfats produced by clover-fed and ryegrass-fed dairy cows. F. H. McDowall and W. A. McGillivray

Studies on the properties of New Zealand butterfat. VII. Effect of the stage of maturity of ryegrass fed to cows on the characteristics of butterfat and its carotene and vitamin A contents. F. H. MCDowALL and W. A. McGillivray

Studies on the properties of New Zealand butterfat. VIII. The fatty acid composition of the milk fat of cows grazing on ryegrass at two stages of maturity and the composition of the ryegrass lipids. J. C. HAWKE .

Studies on the $\kappa$-casein complex. I. The release of sialic acid-containing material by rennin. R. BEeby + . . . . . . . 7

The composition of Iraqi sheep's milk. H. T. NeJrM $\quad$ - _ . . $\quad$ - 81

The incidence of bacteria in cheese milk and Cheddar cheese and their association with flavour. J. G. Franklin and M. Elisabeth Sharpe .

The preparation of $\kappa$-casein. R. D. HrLl . . . . . . . . 101

Reviews of the Progress of Darry Scrence. Section F. Milk-borne disease. P. W. Bothwell . . . . . . . . . 